\title{
EMILIO JOSÉ ARMAZA ARMAZA: EL TRATAMIENTO PENAL DEL QUEBRANTAMIENTO DE UNA ORDEN DE CUARENTENA: LA PROTECCIÓN DE LA SALUD (INDIVIDUAL Y PÚBLICA) Y OTROS DERECHOS EN JUEGO ${ }^{1}$
}

\section{THE CRIMINAL TREATMENT OF THE BREACH OF A QUARANTINE ORDER: THE PROTECTION OF PUBLIC AND INVIDIDUAL HEALTH AND OTHER RIGHTS AT STAKE}

\begin{abstract}
RESUMEN: En el presente trabajo se analiza la idoneidad de nuestro ordenamiento jurídico-penal para hacer frente al hipotético supuesto en el que una persona sometida a un régimen de aislamiento por razones de bioseguridad (es decir, a una "cuarentena" debido a que es portadora de una enfermedad grave) decida hacer caso omiso a las indicaciones de las autoridades sanitarias (o, en su caso, al Juez), fugándose de las instalaciones hospitalarias en las que se encuentra privado de su libertad. Además de la identificación y análisis de los derechos o intereses en juego (salud individual, salud pública, libertad ambulatoria, etc.), propondremos la creación de un nuevo tipo penal para superar la laguna legislativa que identificaremos.
\end{abstract}

ABSTRACT: This paper analyzes the suitability of our legal-criminal system to deal with the hypothetical case in which a person subjected to a biosecurity isolation regime (that is, to a "quarantine" because he is a carrier of a serious illness) decides to ignore the advice of the health authorities (or, if applicable, the Judge), escaping from the hospital facilities in which he is deprived of his liberty. In addition to the identification and analysis of rights or interests at stake (individual health, public health, freedom of movement, etc.), we will propose the creation of a new criminal offense to overcome the legislative gap that we will identify.

PALABRAS CLAVE: Derecho penal, Cuarentena, Delitos contra la salud pública, Bioseguridad.

KEYWORDS: Criminal Law, Quarantine, Crimes against public health, Biosecurity.

\section{Introducción}

Hace poco más de dos años, concretamente el 20 de Julio de 2014, un abogado liberiano (el Sr. P. Sawyer) que trabajaba como alto funcionario del

\footnotetext{
1 Profesor de Derecho Penal de la Universidad de Deusto. Investigador Postdoctoral en Derecho y Genoma Humano de la Universidad del País Vasco UPV/EHU
} 
Ministerio de Economía de su país, viajó hacia el vecino país de Nigeria, concretamente a su capital, la ciudad de Lagos. En aquellos momentos diversos países de África occidental (entre ellos Liberia, Guinea y Sierra Leona) se enfrentaban a una dura lucha en contra del brote de Ébola más grande de su historia reciente. Por el contrario, y este dato ha de ser resaltado, para cuando se produjeron los hechos que vamos a relatar, todavía no se había reportado ni un solo caso de contagio de Ébola en Nigeria (al menos en dicho periodo de años).

Ahora bien, comentábamos que un alto funcionario del Ministerio de Economía de Liberia (país azotado por la crisis biológica que acabamos de mencionar) viajó a la capital de Nigeria; y este hecho no tendría por qué ser significativo, de no haber sido porque el funcionario en cuestión fue posteriormente conocido como el "paciente cero" (index case) de la introducción del virus del Ébola en Nigeria. En efecto, las primeras alarmas, que saltaron cuando el personal sanitario del aeropuerto de Lagos fue requerido para atender a un pasajero que se había desplomado en el momento del desembarque, fueron confirmadas unas horas después cuando, ya en el hospital, se realizaron las pruebas respectivas y fue ratificado el hecho de que el funcionario liberiano padecía y, desde luego, era portador del mortal virus.

A pesar de lo dicho, y poco después de que el sujeto en cuestión recuperase momentáneamente las fuerzas y el ánimo, y a pesar de haber sido pormenorizadamente informado de su delicada situación, el funcionario manifestó al personal sanitario que le atendía su enérgico rechazo a los cuidados y tratamientos que le fueron ofrecidos en el centro de de salud, así como su deseo de abandonar el hospital en ese mismo momento. Desde luego, las autoridades del hospital, teniendo en cuenta el tipo de enfermedad a la que expondría eventualmente a los habitantes de la ciudad de Lagos y, por supuesto, a los habitantes de toda Nigeria ${ }^{2}$, decidieron hacer caso omiso a las peticiones del funcionario liberiano $\mathrm{y}$, todo lo contrario, ordenaron su aislamiento en los espacios adecuados para tal fin. Ahora bien, la respuesta del funcionario en cuestión no se hizo esperar. Sumamente exacerbado y enfurecido, extrajo las cánulas que le habían sido conectadas al cuerpo, se desnudó y comenzó a miccionar dirigiendo los fluidos que expulsaba hacia la zona donde se encontraban los miembros del equipo de sanitarios que en ese momento le atendían, con el fin de provocar que se apartasen de su camino y así poder huir del centro de salud en el que se encontraba detenido.

Debemos indicar que el incidente en cuestión no acabó allí. Después de todo este altercado, el funcionario consiguió contactar con el Embajador liberiano que dirigía la embajada de dicho país en Nigeria, con el fin de poner en su conocimiento los pormenores de su delicada situación. La respuesta del Embajador fue asombrosa: Se puso en contacto con las autoridades del hospital donde estaba aislado su conciudadano con el fin de comunicarles que iba a presentar una denuncia por el delito de detención ilegal dado que con su

${ }^{2}$ A ello se puede añadir, por qué no decirlo, que con dicha conducta se ponía también en peligro de contagio a los habitantes de los países con los que Nigeria mantiene conexiones terrestres o aéreas. 
comportamiento estaban restringiendo la libertad ambulatoria de una persona que gozaba de "inmunidad diplomática". Desde luego no dejó de hacer referencia a las gravísimas consecuencias que este incidente traería para las relaciones políticas, económicas y sociales establecidas entre ambos países.

Para terminar con este breve relato, debemos indicar que a pesar de la enorme presión política a la que fueron sometidas las autoridades hospitalarias donde se encontraba aislado el paciente en cuestión, la respuesta fue siempre la misma. Dicha persona debía ser sometida a un régimen de cuarentena hasta que se descarten los riesgos para la salud pública derivados de un eventual contagio del Ebolavirus. En las horas siguientes, para hacer efectiva la contención del portador de esta mortal enfermedad, varios trabajadores del hospital tuvieron que hacer uso de la fuerza física para poder evitar que la fuga del paciente ponga en riesgo la salud y la vida no sólo de los habitantes de la ciudad de Lagos, sino de toda Nigeria, así como de los países vecinos en los que aun no se habían reportado casos de Ébola.

El señor P. Sawyer, es decir, el paciente infectado, murió cuatro días después de estos incidentes (concretamente el 24 de julio). No fue la única persona que falleció ese año en Lagos a causa de esta terrible enfermedad; también murieron cuatro de los miembros del personal sanitario que retuvieron físicamente al funcionario liberiano, así como otros cuatro civiles que adquirieron el virus de forma indirecta. Cabe indicar que otras once personas fueron aisladas y puestas en cuarentena por haber estado directamente expuestas al virus, aunque afortunadamente, ninguna de ellas padeció finalmente la enfermedad.

Ahora bien, debemos recordar que, aunque con grandes diferencias, en España hemos vivido un incidente que, si bien ha pasado relativamente desapercibido, sumió a nuestra población en una situación de peligro que, quizás, no debería ser relativizada. En efecto, la hoy famosa enfermera que consiguió vencer al Ebolavirus, acudió a un centro de belleza situado en Alcorcón con el fin de depilarse ciertas partes del rostro y se presentó,además,a una oposición que se desarrolló en la Universidad Complutense (estando muy próxima a cientos de personas) cuando ya era portadora del mortal virus. En este sentido, resultan difíciles de identificar, así como de explicar las razones por las cuales dicha enfermera no tuvo ningún reparo para realizar las actividades enumeradas en este párrafo, aun cuando conscientemente decidió adoptar ciertas medidas de precaución en el interior de su domicilio con el fin de evitar que la enfermedad se transmita a su marido (recordemos que ambos decidieron dormir en camas distintas, así como usar baños diferentes).

Estos ejemplos, uno extraído de la experiencia internacional y el otro del incidente biológico más conocido en nuestro país, quizás puedan enseñarnos que, en el contexto de una crisis biológica, nuestra sociedad podría tener que hacer frente al comportamiento de ciertas personas que rechazan y se niegan a ser sometidas a un régimen de aislamiento por razones sanitarias o de bioseguridad (es decir, a lo que coloquialmente conocemos con el nombre de cuarentena) o que, sin negarse a acatar una medida de esta naturaleza, 
adoptan conscientemente comportamientos que pueden poner en peligro la salud pública. La motivación de este tipo de conductas, desde luego, podría ser de lo más diversa. Algunas personas, sumamente asustadas, simplemente querrán volver a casa;por el contrario, otras tal vez actúen en el marco de una actividad terrorista $^{3}$, o bien deseen transmitir la enfermedad a más personas con el fin de presionar al Estado para conseguir financiación para investigaciones o tratamientos para dicha.

En cualquier caso, lo que a nosotros nos interesa resaltar en esta oportunidad es que, con independencia de la motivación, nos encontramos frente a un tipo de conductas que ponen en peligro la vida y salud individual de las personas que finalmente resultan contagiadas, así como la salud pública del colectivo de ciudadanos expuestos (de forma concreta o abstracta) a una enfermedad determinada. Ahora bien, desde la perspectiva del Derecho Penal nos interesa analizar la idoneidad de nuestra legislación penal para prevenir y, en su caso, sancionar este tipo de conductas.

\section{El internamiento por razones de bioseguridad}

Antes de empezar con el análisis del papel que juega el Derecho Penal ante la quiebra de una orden cuarentena, procede preguntarnos si existeen nuestro ordenamiento jurídico una base legal que permita a la Administración restringir la libertad ambulatoria de una persona, con el argumento de que existe el riesgo de que sea portador de una enfermedad que pueda poner en peligro la vida o la salud de los demás ciudadanos.

Una primera aproximación a esta cuestión nos ha de llevar, necesariamente, al examen de lo dispuesto en el Artículo 25.3 de la Constitución (CE78) que, recordemos, establece con claridad que "La Administración civil no podrá imponer sanciones que, directa o subsidiariamente, impliquen privación de libertad". Como sabemos, este precepto tiene su origen en la necesidad de dibujar los límites de las competencias de los órganos penales y de los de la Administración, límites que, con anterioridad a la CE78 eran sumamente difusos y que daban lugar a que, en no pocas ocasiones, la sanción administrativa, además de consistir en la privación de la libertad, fuese incluso más rigurosa que la sanción penal. En cualquier caso, hemos de resaltar que el precepto constitucional aludido hace referencia, única y exclusivamente, a la prohibición que tiene la Administración para imponer "sanciones" que, de forma directa o indirecta, impliquen la privación de libertad. Ahora bien, como sabemos, la noción de "sanción", desde luego, ha sido profundamente estudiada tanto en el marco del Derecho Penal como en sede del Derecho Administrativo Sancionador. Sin ánimo de realizar un análisis pormenorizado de esta cuestión, sí que conviene poner de manifiesto que en los estudios desarrollados en el marco de ambas esferas del saber jurídico, es constante la idea de que una de las principales características de las sanciones

\footnotetext{
${ }^{3}$ SÁnChez Moreno, Manuel / García Estévez, Gustavo, "La amenaza bioterrorista procedente del yijadismo", en Bioseguridad, Derecho y Defensa, CUADRADO RUIZ, Ma Ángeles / PeñA FreIRE, Antonio (Eds.), Editorial Universidad de Granada, Granada, 2013, pp. 166-170.
} 
administrativas y penales, está constituida precisamente por la idea de "retribución". De esta manera, ambos tipos de consecuencias jurídicas se configuran como mecanismos de clara naturaleza retributiva, en el sentido de que posibilitan la reafirmación del ordenamiento jurídico que ha sido previamente quebrantado, así como la expiación de la culpabilidad por parte de aquellos infractores que aceptan voluntariamente la sanción como una consecuencia justa por la infracción que han cometido.

En cualquier caso, lo que sí debe quedar sumamente claro es que la eventual restricción de la libertad ambulatoria de un individuo con el argumento de que existe el riesgo de que sea portador de una enfermedad que pueda poner en peligro la vida o la salud de los demás ciudadanos no constituye, en modo alguno, una sanción. La constatación de que dicha persona sea portadora de una enfermedad contagiosa y muy grave (como el Ébola) no forma parte del catálogo de supuestos (delitos o infracciones administrativas) que habilitan, bien al Derecho Penal, o bien al Derecho Administrativo Sancionador, para imponer una sanción determinada. Nos encontramos, por lo tanto, frente a una medida administrativa que restringe o limita el derecho a la libertad ambulatoria, pero que al carecer por completo de cualquier tipo de contenido de naturaleza retributiva (lo cual nos lleva a la conclusión de que no puede ser considerada como una sanción), podría ser perfectamente impuesta por la Administración, sin que por ello se vulnere el mandato constitucional anteriormente reseñado.

Son dos las fuentes legislativas que, en nuestro ordenamiento jurídico, regulan los supuestos en los que se puede adoptar una medida de aislamiento por razones de bioseguridad. La primera de ellas se encuentra en la Ley Orgánica 3/1986, de 14 de abril, de Medidas Especiales en Materia de Salud Pública. En efecto, el artículo 2 de dicha norma establece que "Las autoridades sanitarias competentes podrán adoptar medidas de reconocimiento, tratamiento, hospitalización o control cuando se aprecien indicios racionales que permitan suponer la existencia de peligro para la salud de la población debido a la situación sanitaria concreta de una persona o grupo de personas 0 por las condiciones sanitarias en que se desarrolle una actividad". Asimismo, conforme a lo dispuesto por el artículo 3 de la misma LO"Con el fin de controlar las enfermedades transmisibles, la autoridad sanitaria, además de realizar las acciones preventivas generales, podrá adoptar las medidas oportunas para el control de los enfermos, de las personas que estén o hayan estado en contacto con los mismos y del medio ambiente inmediato, así como las que se consideren necesarias en caso de riesgo de carácter transmisible".De otro lado, resulta interesante destacar que la Ley 29/1998, de 13 de julio, reguladora de la Jurisdicción Contencioso-administrativa, establece en su artículo 8.6 que "(....) corresponderá a los Juzgados de lo Contencioso-administrativo la autorización o ratificación judicial de las medidas que las autoridades sanitarias consideren urgentes y necesarias para la salud pública e impliquen privación o restricción de la libertad o de otro derecho fundamental".

Nos encontramos, por lo tanto, frente a una medida prevista en nuestro ordenamiento jurídico cuya justificación se encuentra, como no podía ser de otra manera, la necesidad de evitar la producción de un mal mayor 
(partiéndose por lo tanto, de un análisis "consecuencialista" de las hipotéticas variantes de la situación $)^{4}$. Se configura, pues, una situación análoga a la figura penal conocida con el nombre de "estado de necesidad justificante" por medio de la cual, recordemos, el Estado permite a un actor determinado sacrificar un bien jurídico de menor valor -la libertad ambulatoria de una persona concreta, por ejemplo - con el fin de salvaguardar otro u otros de mayor valor — la vida 0 la integridad personal de varios ciudadanos-).

Ahora bien, lo dicho hasta aquí nos lleva a la conclusión de que, conforme a nuestra tradición dogmática $\mathrm{y}$, desde luego, a lo dispuesto por nuestro ordenamiento jurídico, resulta claramente aceptable y, por supuesto, viable imponer, incluso coactivamente, una restricción a la libertad ambulatoria de una persona que presumiblemente sea portadora de una enfermedad grave y que, por ello, pueda poner en peligro la vida o la salud de sus conciudadanos. En otras palabras, hemos previsto la posibilidad de sacrificar ciertos derechos (entre ellos, concretamente, el derecho a la libertad ambulatoria) en aras de brindar protección a la salud pública frente a situaciones de alto riesgo.

\section{El Derecho Penal ante la quiebra de una medida de cuarentena}

Una vez que hemos identificado a la "salud pública" como el valor iusfundamental que justifica el sacrificio de la libertad ambulatoria por razones de bioseguridad, mediante la imposición de una medida de cuarentena, procede formular la siguiente pregunta: ¿Dispone nuestro ordenamiento jurídico-penal de ciertas herramientas destinadas a sancionar a aquellas personas que consiguen evadir la medida de aislamiento que les ha sido legítimamente impuesta, bien huyendo del sitio donde se encontraban ya recluidos, o bien evitando ser detenidos antes de haber sido aislados?

\section{a) La salud pública como bien jurídico afectado}

La respuesta a la pregunta planteada en el párrafo anterioresta condicionada, nuevamente, a la identificación delel bien jurídico penalmente relevante que ha sido lesionado o que, en su caso, ha sido puesto en peligro (concreto o abstracto) de lesión mediante la conducta de quiebra de la medida de cuarentena. Ello, desde luego, en aras de garantizar el respeto al Principio de lesividad $u$ ofensividad (fundamental para el Derecho Penal) por medio del cual, recordemos, se condiciona la habilitación de la intervención penal a la previa lesión o, al menos, puesta en peligro de lesión de uno de los bienes jurídicos penalmente relevantes ${ }^{5}$.

\footnotetext{
${ }^{4}$ SInGER, Peter, Ética práctica, Segunda edición, HeRRERA Bonet, Rafael (Trad.), Cambridge University Press, Madrid, 2003, pp. 6-11.

${ }^{5}$ Boldova Pasamar, Miguel Ángel, "Los principios del Derecho Penal", en Derecho Penal. Parte General. Introducción. Teoría Jurídica del Delito, ROMEOCASABONA, Carlos María / SolA RECHE, Esteban / Boldova PASAMAR, Miguel Ángel (Coords.), Editorial Comares, Granada, 2016, pp. 47 y 48.
} 
Entonces, ¿cuál es el bien jurídico que se intentaría proteger en este tipo de situaciones? Recordemos que nos encontramos frente a la hipotética situación en la que una persona portadora de una enfermedad grave e infecciosa quebranta la orden de aislamiento que recae sobre ella. En este sentido, debemos deslindar, en primer lugar, las respuestas penales aplicables al sujeto activo cuando se haya configurado un delito de resultado (por haberse, desde luego, producido un resultado material determinado - como la muerte o la lesión de una o varias personas-). En tales supuestos, como es lógico, serán de aplicación los tipos penales de homicidio o, en su caso, de lesiones (cualificadas por el resultado probablemente) dado que ambos protegen dos bienes jurídicos de naturaleza individual (la vida y la integridad de las personas que han sufrido, efectivamente, la lesión de tales bienes jurídicos).

No obstante, este camino no es, en absoluto, el idóneo para brindar protección al valor iusfundamental que, como hemos visto con anterioridad, ha servido de fundamento para la legitimación ética y jurídica de la aplicación de la medida de aislamiento o cuarentena. Nos referimos, concretamente, a la idea de "salud pública", entendida como la salud de la colectividad, más allá de la salud individual —o de la suma de las saludes individuales- ${ }^{6}$. En efecto, no cabe duda que la conducta desplegada en la hipotética situación planteada como supuesto de hecho en esta intervención, resulta particularmente idónea para sumir en un efectivo y real peligro de lesión a dicho bien jurídico; en este sentido, basta un rápido análisis empírico de los casos más emblemáticos de crisis biológicas recientes causadas por enfermedades mortales para darnos cuenta que incluso aunque ninguna persona resulte efectivamente lesionada, son múltiples e incluso inimaginables los riesgos que existen para la salud de la colectividad.

\section{b) La protección penal de la salud pública}

Por las razones anteriormente expuestas, consideramos apropiado realizar una lectura panorámica de los artículos del CP que contienen los delitos contra la salud pública ${ }^{7}$, con el fin de identificar el tipo tipo penal que permita sancionar a quien pone en peligro la salud de la colectividad mediante la quiebra de una medida de cuarentena. En este sentido, podemos indicar que los artículos incorporados en el apartado del CP consagrados a la sanción de los delitos que ponen el peligro la salud pública pueden ser agrupados en los

\footnotetext{
${ }^{6}$ Romeo Malanda, Sergio, "Delitos contra la seguridad colectiva II. Delitos contra la salud pública", en Derecho Penal. Parte Especial. Conforme a las Leyes Orgánicas 1 y 2/2015, de 30 de marzo, RomeoCasabona, Carlos María / Sola ReChe, Esteban / Boldova Pasamar, Miguel Ángel (Coords.), Editorial Comares, Granada, 2016, p. 594. Cabe indicar, asimismo, que la protección penal del bien jurídico aludido, no es sino un reflejo de la tutela constitucional que ha sido dispuesta para tal fin (en efecto, el artículo 43.2 CE señala que "Compete a los poderes públicos organizar y tutelar la salud pública a través de medidas preventivas y de las prestaciones y servicios necesarios. La ley establecerá los derechos y deberes de todos al respecto". CP.

${ }^{7}$ Todos ellos incorporados, como sabemos, en el Capítulo III del Título XVII del Libro II del
} 
siguientes bloques: $1 \stackrel{0}{ }$ Delitos relativos a las sustancias nocivas para la salud 0 productos químicos que puedan causar estragos. $2^{\circ}$ Delitos farmacológicos. $3^{\circ}$ Delito de dopaje deportivo. $4^{\circ}$ Delitos relativos a productos de consumo masivo. Y, 5 을 Delitos relativos al tráfico de drogas.

El primero de estos grupos de infracciones está conformado por los preceptos penales incorporados en los artículos 359 y 360 del CP, por medio de los cuales se sanciona, bajo determinadas condiciones, la elaboración, despacho, suministro o comercio de las sustancias o productos químicos indicados. El segundo grupo, conformado por los delitos recogidos en los artículos 361, 362, 362 bis, 362 ter y 362 quáter del CP, está consagrado a la sanción de los llamados "delitos farmacológicos", por medio de los cuales se sanciona, también en determinados supuestos, una serie de conductas de diversa naturaleza (elaboración, producción, fabricación, importación, exportación, comercialización, etc.) que tienen en común el objeto material del delito (medicamentos y otros productos sanitarios).Por su parte, el tercer grupo está conformado por la modalidad básica, así como por los supuestos agravados del delito de dopaje en el ámbito deportivo (artículo 362 quinquies del CP) castigándose, entre otros comportamientos, la prescripción, dispensa, suministro, ofrecimiento, etc. de sustancias o métodos prohibidos a deportistas (profesionales o no) que deseen aumentar sus capacidades físicas o modificar los resultados de las competiciones en las que participan ${ }^{8}$. En el cuarto grupo de delitos (artículos 363, 364 y 365 del CP) se encuentran tipificadas una serie de conductas por medio de las cuales se afecta la calidad de los productos dirigidos al consumo y que, en términos generales y con la excepción de figuras concretas, tienen en común el objeto material del delito (productos alimentarios).

Por último, en el quinto grupo de infracciones (tipificadas en los artículos 368 y ss.) se sanciona el tipo básico y atenuado, así como las modalidades agravadas del tráfico de drogas tóxicas, estupefacientes o sustancias psicotrópicas, incluyéndose además un precepto por medio del cual se castiga de forma específica la tenencia y tráfico de materiales que pueden ser empleados para la elaboración de las sustancias anteriormente mencionadas (precursores).

En definitiva, esta rápida revisión de la redacción actual de nuestro Código Penal nos permite afirmar que teniendo como base nuestro sistema protección penal de la salud pública ( $\mathrm{y}$, desde luego, el principio de legalidad), no podríamos sancionar a quien, siendo conscientemente portador de una enfermedad pandémica y sumamente letal, pone en peligro la salud de la colectividad mediante la quiebra de una medida de cuarentena. La conducta resulta atípica (nullum crimen, nulla poena sine praevia lege ${ }^{9}$ incluso en aquellos supuestos —más reprochables aún- en los que el autor tuviera la

\footnotetext{
${ }^{8}$ Atienza Macías, Elena / ARmaza Armaza, Emilio José, El dopaje en el Derecho Deportivo actual: análisis y revisión bibliográfica, Editorial Reus, Madrid, 2016, pp. 195 y ss.

${ }^{9}$ Muñoz Conde, Francisco / García ArÁn, Mercedes, Derecho Penal. Parte General. 9a edición, revisada y puesta al día conforme a las Leyes Orgánicas 1/2015 y 2/2015, de 30 de marzo, Tirant lo Blanch, Valencia, 2015, p. 109.
} 
intención de propagar y transmitir la enfermedad a los demás habitantes de la localidad.

Parece, desde luego, una gran paradoja el hecho de que nuestro legislador penal no se haya preocupado por el desarrollo de herramientas, en sede de los delitos contra la salud pública, que permitan prevenir el tipo de comportamientos analizados, a pesar de que sí ha puesto especial interés en la represión de conductas que podrían llegar a tener una escasa (o, incluso, nula) idoneidad para poner en peligro de lesión el bien jurídico en cuestión (por ejemplo, en la SAP Valencia 306/2015, de 20 de abril, se castiga la venta de 1,9 gramos de hachís, con una pureza del $12,5 \%$, como un delito contra la salud pública, con una pena de 7 meses de prisión).

\section{c) Las herramientas penales para la protección frente a las armas biológicas}

Ahora bien, sin perjuicio de la falta de protección de la salud de la colectividad ante estas particulares formas de amenazas, es preciso indicar que en nuestro Código Penal podemos encontrar otros preceptos penales que, en mayor o menor medida, guardan relación con el fenómeno de las crisis biológicas. En efecto, este es el caso de los delitos de: 1ํㅜㄹoducción de armas biológicas (tipificado en el artículo 160.1 del CP y que, según la doctrina mayoritaria, se encuentra orientado a brindar protección a la supervivencia de la especie humana $)^{10}$. $2^{\circ}$ Desarrollo, fabricación, comercialización, tráfico, depósito o empleo de armas biológicas, de guerra, químicas, nucleares o radiológicas 0 de minas antipersonas o municiones en racimo (cuyas modalidades se encuentran tipificadas en los artículos 566.1.1ํ. y 566.2 del CP, que, según opinión mayoritaria, se encuentran orientados a brindar protección al orden público -entendido, bien como la tranquilidad o paz en las manifestaciones colectivas de la vida comunitaria, o bien como la seguridad colectiva o comunitaria-11. $3^{10}$ Inicio de preparación militar para el empleo de armas biológicas, así como la no destrucción de dichas armas con infracción de los tratados o convenios internacionales en los que España sea parte (modalidades delictivas tipificadas en el artículo 566.2 del CP y que también se encuentran orientadas a la protección del orden público).

En cualquier caso, debemos resaltar el hecho de que todos los delitos enumerados en el párrafo anterior se encuentran orientados hacia la protección

\footnotetext{
${ }^{10}$ Romeo Casabona, Carlos María, Genética, Biotecnología y Ciencias Penales, Ediciones de la Pontificia Universidad Javeriana - Grupo Editorial Ibañez, Bogotá, 2009, p. 354; ARMAZA ARMAZA, Emilio José, "Los instrumentos jurídico-penales para lucha contra el bioterrorismo", en Bioterrorismo y Bioseguridad, ROMEO CASABONA, Carlos María (Ed.), Cátedra Interuniversitaria de Derecho y Genoma Humano, Bilbao, 2015, p. 205.

${ }^{11}$ UrRUELA Mora, Asier, "Delitos contra el orden público I. Sedición. Atentados contra la autoridad, sus agentes y los funcionarios públicos, resistencia y desobediencia. Desordenes públicos. Tenencia, tráfico y depósito de armas, municiones o explosivos", en Derecho Penal. Parte Especial. Conforme a las Leyes Orgánicas 1 y 2/2015, de 30 de marzo, RomeoCasabona, Carlos María / Sola Reche, Esteban / Boldova Pasamar, Miguel Ángel (Coords.), Editorial Comares, Granada, 2016, p. 811.
} 
de bienes jurídicos que no se identifican claramente con el valor iusfundamental que sirve de base para la legitimación de la imposición de una medida de aislamiento por razones de bioseguridad, es decir, que no se identifican nítidamente con la protección de la salud de la colectividad.

\section{d) El quebrantamiento de condena y la desobediencia grave a la autoridad}

Por último, cabe indicar que podría discutirse la configuración de alguno de los delitos de quebrantamiento de condena (tipificados en los artículos 468 y ss. del (P), pero hemos de tener en cuenta que tales preceptos únicamente sancionan a quien quebranta una consecuencia jurídica de naturaleza penal ${ }^{12}$; así las cosas, la conducta de quien quebranta de una medida de aislamiento por riesgo biológico (que, recordemos, carece de connotaciones de naturaleza penal) no podría ser subsumida en ninguno de los tipos penales enunciados sin sacrificar el mandado penal (del artículo 4.1 del CP) que prohíbe la aplicación de preceptos penales a casos distintos de los comprendidos expresamente en ellos (prohibición de la analogía in malam partem) ${ }^{13}$. No obstante, resulta interesante mencionar que, al parecer, la única vía que podría, eventualmente, conducir a la sanción de las conductas analizadas se abre por medio del delito de desobediencia grave a la autoridad, a sus agentes o, incluso, al personal de seguridad privada que desarrolle actividades de seguridad privada en cooperación y bajo el mando de las Fuerzas y Cuerpos de Seguridad (tipificado en el artículo 556.1 del CP) ${ }^{14}$.

Ahora bien, cabe resaltar que tanto en el primero (delito de quebrantamiento de condena), como en el segundo de estos supuestos (desobediencia a la autoridad) el bien jurídico protegido tampoco guarda relación alguna con la protección de la salud pública, dado que en el primer caso se protege el interés del Estado en el correcto cumplimiento de las resoluciones judiciales que impongan penas, medidas de seguridad o medidas cautelares ${ }^{15}$; mientras que en el segundo se tutela el llamado "principio de autoridad", entendido como el correcto ejercicio de las funciones que poderes públicos ejercen al servicio de la colectividad ${ }^{16}$.

\footnotetext{
${ }^{12}$ Muñoz CONDE, Francisco, Derecho Penal. Parte Especial. 20 edición, completamente revisada y puesta al día conforme a las Leyes Orgánicas 1/2015 y 2/2015, de 30 de marzo, Tirant lo Blanch, Valencia, 2015, pp. 837 y 838.

${ }^{13}$ Boldova Pasamar, Miguel Ángel, op cit., p. 44; Muñoz Conde, Francisco / García Arán, Mercedes, op cit., p. 118.

${ }^{14}$ FLORES MENDOZA, Fátima, "Delitos contra la administración de justicia", en Derecho Penal. Parte Especial. Conforme a las Leyes Orgánicas 1 y 2/2015, de 30 de marzo, RomeoCasabona, Carlos María / Sola Reche, Esteban / Boldova Pasamar, Miguel Ángel (Coords.), Editorial Comares, Granada, 2016, p.752.

${ }^{15}$ Flores MendozA, Fátima, op. cit., p.752.

${ }^{16}$ UrRuela Mora, Asier, op. cit., p. 797.
} 


\section{REFLEXIONES FINALES}

Llegados a este punto, la primera cuestión que hemos de resaltar está relacionada con el hecho de que en la actualidad no contamos con una herramienta penal destinada a sancionar a quien, siendo conscientemente portador de una enfermedad grave ( $\mathrm{y}$, claro está, contagiosa), no adopta las medidas apropiadas para evitar la puesta en peligro de la salud pública, o bien quebranta las medidas previamente impuestas por la administración (orden de cuarentena).A la luz de los gravísimos peligros que pueden derivar de las crisis biológicas y, concretamente, del peligropara la salud de la colectividad que puede desencadenarse en el marco de una conducta de quiebra de una medida de cuarentena, a primera vista no parece haber grandes inconvenientes para afirmar que es necesaria la inclusión de un nuevo tipo penal que sancione a quienes adopten este tipo de comportamientos.

Ahora bien, resulta sumamente importante manifestar que una nueva propuesta de "expansión del Derecho Penal" ha de venir acompañada de un profundo debate en relación con la justificación y, desde luego, legitimación, de este eventual proceso de criminalización primaria debido, fundamentalmente a que, como sabemos, la aplicación del Derecho Penal supone, para quien padece sus consecuencias jurídicas, la privación o menoscabo de importantísimos derechos e intereses. En este sentido, creemos que no sólo es conveniente, sino que es sumamente necesario el análisis de este eventual proceso de criminalización a la luz de los principios fundamentales del Derecho Penal, con el fin de evitar la inclusión de un precepto incompatible con las garantías del Estado de Derecho.

Así las cosas, resulta indispensable analizar las implicaciones que pueden tener para esta materia los principios de esencialidad o fragmentariedad (en efecto, si este hipotético conflicto "jurídico-penal" puede ser resuelto eficazmente por medio de otras formas de control social formal -formas menos costosas en el plano iusfundamental- es probable que debamos decantarnos por el uso de éstas, en lugar de recurrir a la herramienta más cruenta de la que disponemos), de lesividad (en efecto se han de determinar, cualitativa y cuantitativamente, los límites que deben dibujar la línea que separa una lesión —o puesta en peligro de lesión-con relevancia penal, de una lesión -o puesta en peligro de lesión- que carece de ella), de interés público y correspondencia con la realidad (a fin de desarrollar un sistema penal que, aunque pueda llevar la etiqueta de "simbólico", sea eficaz cuando se presenten ciertas oportunidades para su aplicación), de certeza y taxatividad (con el fin de desarrollar herramientas que no afecten la seguridad jurídica), de culpabilidad (a efectos de prevenir la represión de personas a las que quizás no se les debería reprochar su conducta -respetando, por ello, el principio de inexigibilidad de obediencia al derecho-) y, en fin, los principios relacionados con la orientación de los fines de la pena (establecimiento de penas proporcionales y humanas).

\section{REFERENCIAS BIBLIOGRÁFICAS}


Armaza ArmazA, Emilio José, "Los instrumentos jurídico-penales para lucha contra el bioterrorismo", en Bioterrorismo y Bioseguridad, ROMEO CASABONA, Carlos María (Ed.), Cátedra Interuniversitaria de Derecho y Genoma Humano, Bilbao, 2015.

Atienza Macías, Elena / Armaza Armaza, Emilio José, El dopaje en el Derecho Deportivo actual: análisis y revisión bibliográfica, Editorial Reus, Madrid, 2016.

Boldova Pasamar, Miguel Ángel, "Los principios del Derecho Penal", en Derecho Penal. Parte General. Introducción. Teoría Jurídica del Delito, RomeoCasabona, Carlos María / Sola Reche, Esteban / Boldova Pasamar, Miguel Ángel (Coords.), Editorial Comares, Granada, 2016.

Flores MendozA, Fátima, "Delitos contra la administración de justicia", en Derecho Penal. Parte Especial. Conforme a las Leyes Orgánicas 1 y 2/2015, de 30 de marzo, RomeoCasABOna, Carlos María / Sola ReCHE, Esteban / Boldova PASAMAR, Miguel Ángel (Coords.), Editorial Comares, Granada, 2016.

Muñoz Conde, Francisco / García ARán, Mercedes, Derecho Penal. Parte General. $9^{a}$ edición, revisada y puesta al día conforme a las Leyes Orgánicas 1/2015 y 2/2015, de 30 de marzo, Tirant lo Blanch, Valencia, 2015.

MuÑoz CONDE, Francisco, Derecho Penal. Parte Especial. 20aㅡ edición, completamente revisada y puesta al día conforme a las Leyes Orgánicas 1/2015 y 2/2015, de 30 de marzo, Tirant lo Blanch, Valencia, 2015.

Romeo Casabona, Carlos María, Genética, Biotecnología y Ciencias Penales, Ediciones de la Pontificia Universidad Javeriana - Grupo Editorial Ibañez, Bogotá, 2009.

Romeo Malanda, Sergio, "Delitos contra la seguridad colectiva II. Delitos contra la salud pública", en Derecho Penal. Parte Especial. Conforme a las Leyes Orgánicas 1 y 2/2015, de 30 de marzo, RomeoCASABONA, Carlos María / Sola RECHE, Esteban / Boldova PASAMAR, Miguel Ángel (Coords.), Editorial Comares, Granada, 2016.

Sánchez Moreno, Manuel / García Estévez, Gustavo, "La amenaza bioterrorista procedente del yijadismo", en Bioseguridad, Derecho y Defensa, Cuadrado Ruiz, Mà Ángeles / PeÑa Freire, Antonio (Eds.), Editorial Universidad de Granada, Granada, 2013.

Singer, Peter, Ética práctica, Segunda edición, Herrera Bonet, Rafael (Trad.), Cambridge University Press, Madrid, 2003,

URRUela Mora, Asier, "Delitos contra el orden público I. Sedición. Atentados contra la autoridad, sus agentes y los funcionarios públicos, resistencia y desobediencia. Desordenes públicos. Tenencia, tráfico y depósito de armas, municiones o explosivos", en Derecho Penal. Parte Especial. Conforme a las Leyes Orgánicas 1 y 2/2015, de 30 de marzo, RomeoCASABONA, Carlos María / Sola ReCHE, Esteban / Boldova PASAmar, Miguel Ángel (Coords.), Editorial Comares, Granada, 2016. 